\title{
Voluntary Exercise Decreases Amyloid Load in a Transgenic Model of Alzheimer's Disease
}

\author{
Paul A. Adlard, Victoria M. Perreau, ${ }^{\star}$ Viorela Pop, ${ }^{\star}$ and Carl W. Cotman \\ Institute for Brain Aging and Dementia, University of California, Irvine, Irvine, California 92697-4540
}

\begin{abstract}
Alzheimer's disease $(\mathrm{AD})$ is a progressive neurodegenerative disorder for which there are few therapeutics that affect the underlying disease mechanism. Recent epidemiological studies, however, suggest that lifestyle changes may slow the onset/progression of AD. Here we have used TgCRND8 mice to examine directly the interaction between exercise and the AD cascade. Five months of voluntary exercise resulted in a decrease in extracellular amyloid- $\beta(\mathrm{A} \beta)$ plaques in the frontal cortex $(38 \% ; p=0.018)$, the cortex at the level of the hippocampus $(53 \% ; p=0.0003)$, and the hippocampus $(40 \% ; p=0.06)$. This was associated with decreased cortical A $\beta 1-40(35 \% ; p=$ $0.005)$ and $\mathrm{A} \beta 1-42(22 \% ; p=0.04)(\mathrm{ELISA})$. The mechanism appears to be mediated by a change in the processing of the amyloid precursor protein (APP) after short-term exercise, because 1 month of activity decreased the proteolytic fragments of APP [for $\alpha$-Cterminal fragment ( $\alpha$-CTF), $54 \%$ and $p=0.04$; for $\beta$-CTF, $35 \%$ and $p=0.03$ ]. This effect was independent of mRNA/protein changes in neprilysin and insulin-degrading enzyme and, instead, may involve neuronal metabolism changes that are known to affect APP processing and to be regulated by exercise. Long-term exercise also enhanced the rate of learning of TgCRND8 animals in the Morris water maze, with significant $(p<0.02)$ reductions in escape latencies over the first 3 (of 6) trial days. In support of existing epidemiological studies, this investigation demonstrates that exercise is a simple behavioral intervention sufficient to inhibit the normal progression of AD-like neuropathology in the TgCRND8 mouse model.
\end{abstract}

Key words: Alzheimer’s disease; exercise; amyloid; transgenic; APP; TgCRND8

\section{Introduction}

Alzheimer's disease $(\mathrm{AD})$ is a progressive neurodegenerative disease that represents the eighth leading cause of death in people $\geq 65$ years of age (Mayeux, 2003), affecting 20-30 million people worldwide (Selkoe and Schenk, 2003). Current therapeutics temporarily ameliorate the symptoms of $\mathrm{AD}$, but few affect the underlying disease mechanism (Selkoe and Schenk, 2003). A number of epidemiological studies, however, suggest that simple lifestyle changes may be sufficient to slow the onset and progression of AD (Pope et al., 2003). A recent retrospective case control study (Friedland et al., 2001), for example, demonstrated that patients with $\mathrm{AD}$ were less active (both intellectually and physically) in midlife and that inactivity was associated with a $250 \%$ increased risk of developing AD. Similarly, a prospective study (Laurin et al., 2001) also demonstrated that physical activity was protective against the development of cognitive impairment, Alzheimer's disease, and dementia of any type, with the highest activity group showing a $60 \%$ decrease in the incidence of $\mathrm{AD}$. Other studies, however, have not reported a similar association. In a smaller population-based sample (Wilson et al., 2002), for

Received Nov. 29, 2004; revised March 2, 2005; accepted March 15, 2005.

This work was supported by National Institute on Aging Grant AG-13411-04 and the Christopher Reeve Paralysis Foundation. We thank Dr. Hill for statistical analysis. We also thank Floyd Sarsoza, Mihaela Nistor, and Dr. Head for assistance with this manuscript.

*V.M.P. and V.P. contributed equally to this work.

Correspondence should be addressed to Dr. Paul Adlard, Institute for Brain Aging and Dementia, 1113 Gillespie Neuroscience Research Facility, University of California, Irvine, Irvine, CA 92697-4540. E-mail: padlard@uci.edu. D01:10.1523/JNEUROSCI.0496-05.2005

Copyright $\odot 2005$ Society for Neuroscience $\quad$ 0270-6474/05/254217-05\$15.00/0 example, weekly hours of physical activity were not related to the risk of development of AD. Although such epidemiological studies have addressed the potential effect of exercise on the development of $\mathrm{AD}$, there have been no basic research investigations performed to test the interaction between exercise and AD.

In this study, therefore, we have used the TgCRND8 mouse model (Chishti et al., 2001) of AD to test directly the hypothesis that long-term voluntary exercise would impact the normal progression of AD-like neuropathology. Furthermore, we have sought to assess a number of mechanistic possibilities to account for the observed phenomena as well as to examine the effect of exercise on the performance of TgCRND8 animals in the Morris water maze.

\section{Materials and Methods}

All animal procedures were approved by the Institutional Animal Care and Use Committee for the University of California, Irvine (Irvine, CA). We used the TgCRND8 mouse line (courtesy of David Westaway, University of Toronto, Toronto, Ontario, Canada) (maintained on the background strain $\mathrm{B} 6 \mathrm{C} 3 \mathrm{~F} 1 / \mathrm{J})$ that encodes a double-mutant form of amyloid precursor protein (APP) 695 (KM670/671NL + V717F). Female animals were housed singly in either a regular cage or a cage equipped with a running wheel (Nalgene; Nalge Nunc, Rochester, NY) for 1 month from 6 weeks of age (short-term, $n=5$ exercise and $n=3$ sedentary) or for 5 months starting at 1 month of age (long-term, $n=5$ exercise and $n=5$ sedentary). There was no difference in survival among any of the groups $(p>0.8)$. Animals were decapitated, and either both halves of the brain were microdissected (short-term) or one-half was microdissected and the other one-half was postfixed in $4 \%$ paraformaldehyde (long-term). All tissues for biochemical analyses were stored at $-80^{\circ} \mathrm{C}$, whereas tissue 
processed for immunohistochemistry $(50 \mu \mathrm{m}$ sections) was stored at $4^{\circ} \mathrm{C}$.

Immunohistochemistry. For immunohistochemistry, brains were sectioned in the coronal plane at $50 \mu \mathrm{m}$ thickness with the use of a vibratome; then standard single-labeling fluorescence techniques were used. All sections were processed concurrently, and extracellular amyloid- $\beta(\mathrm{A} \beta)$ load was detected by using the antibody 4G8 (1:500; Signet Laboratories, Dedham, MA). The degree of $\mathrm{A} \beta$ immunoreactivity was assessed with NIH Image 1.63, as described previously (Cummings and Cotman, 1995). Briefly, for each animal, the sections were captured in the cortex (approximately seven random sections at the level of the frontal cortex and another approximately seven random sections in the cortex at the level of the hippocampus) and the hippocampus $(\sim 15$ images from each animal, all of which were collected in a consistent manner and covered the area of the hippocampus). Captured images then were imported into NIH Image, and an intensity threshold level was set that allowed for discrimination between plaque and background labeling. The total number of plaqueassociated pixels was calculated in each section, and then the $A \beta$ load was calculated.

$A \beta$ ELISA. A $\beta$ was quantitated by sandwich ELISA. Briefly, plates were coated with the capture antibody $(5 \mu \mathrm{g} / \mathrm{ml}$; gift from Dr. Van Nostrand, State University of New York, Stony Brook, NY) and incubated overnight at $4^{\circ} \mathrm{C}$. Then the antibody was discarded, and blocking buffer was added. After overnight incubation and several PBS washes, antigen capture buffer was applied to all wells. Samples then were homogenized in radioimmunoprecipitation assay buffer and centrifuged (14,000 rpm for $1 \mathrm{~h}$ ); the pellet was resuspended in an equal volume of $70 \%$ formic acid. Samples were centrifuged again $(14,000 \mathrm{rpm}$ for $1 \mathrm{~h})$ and, together with standards, applied to the plate in duplicate and incubated overnight. Wells were rinsed in PBS, the HRP-conjugated secondary antibody (A $\beta 40$ at 1:1000; $A \beta 42$ at 1:500; gift from Dr. Eckman) was applied, and the wells were incubated overnight. Plates were rinsed in PBS/Tween 20 and PBS and then developed by the addition of TMB solution; the reaction was stopped with phosphoric acid. Next, the plate was read at 450 $\mathrm{nm}$ on a plate reader. See supplemental material (available at www.jneurosci.org) for details of solutions.

Secretase activity. Secretase activity was assessed by using the $\alpha-, \beta$, and $\gamma$-secretase kits (R \& D Systems, Minneapolis, MN), according to the manufacturer's instructions.

$m R N A$ and protein quantitation. Microdissected brain regions were extracted in Trizol (Invitrogen, San Diego, CA) to allow for the collection of both mRNA and protein. Total RNA was extracted, and RNA quality was assessed on an Agilent Technologies (Palo Alto, CA) bioanalyzer system. Each gene was amplified in multiplex reverse transcription (RT)PCRs, and expression levels were normalized to an internal control gene, cytoplasmic $\mathrm{C}_{1}$-tetrahydrofolate synthase $\left(\mathrm{C}_{1}\right.$ THF synthase; see supplemental material, available at www.jneurosci.org). Oligonucleotides used for amplification were purchased from Qiagen (Valencia, CA) (see supplemental material, available at www.jneurosci.org). RT-PCR amplifications were performed by using OneStep RT-PCR kits (Qiagen) with $0.2-$ $0.4 \mu \mathrm{g}$ of total RNA in $10 \mu \mathrm{l}$ reaction volumes in a Robocycler PCR machine (Stratagene, La Jolla, CA) with hot top. Then $1 \mu$ l of each reaction was diluted with $4 \mu \mathrm{l}$ of water and analyzed on a DNA-500 LabChip (Agilent Technologies). For each gene, the conditions were optimized to produce yields in the linear range of detection with the lowest cycle number. For neprilysin, $0.4 \mu \mathrm{g}$ of total RNA was used with 25 amplification cycles; for insulin-degrading enzyme (IDE), $0.2 \mu \mathrm{g}$ of total RNA was used with 27 amplification cycles. The corrected area of each amplification product was used to calculate the relative amount of the gene of interest, expressed as a percentage of the $\mathrm{C}_{1}$ THF synthase amplification product.

For Western blotting, the concentrations of protein samples obtained

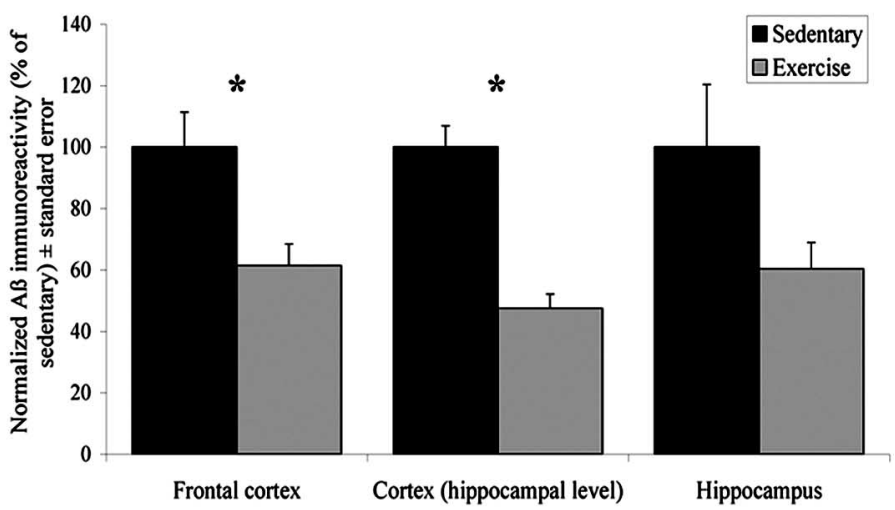

(reagents A and B; Pierce, Rockford, IL). Aliquots of the raw samples were brought to the same concentration with extraction buffer and then prepared in loading buffer, boiled for $5 \mathrm{~min}$ at $100^{\circ} \mathrm{C}$, and stored at $-20^{\circ} \mathrm{C}$ until ready for use on the Western blot (for buffer components, see supplemental material, available at www.jneurosci.org). Standard Western blot methods were used (see supplemental material, available at www.jneurosci.org). The following antibodies were used: neprilysin (monoclonal CD10, 1:50; Novocastra Laboratories, Newcastle upon Tyne, UK), 6E10 (monoclonal, 1:2000; Signet Laboratories), 22C11 (monoclonal, 1:500; Chemicon, Temecula, CA), CT20 (polyclonal, 1:250; courtesy of Pritam Das, Mayo Clinic, Jacksonville, FL), and IDE (polyclonal, 1:5000; courtesy of Dennis Selkoe, Brigham and Women's Hospital, Center for Neurologic Diseases, Boston, MA). $\beta$-Actin (polyclonal, 1:5000; Abcam, Cambridge, MA) was used for normalization. All blots were detected with appropriate secondary antibodies. Proteins were quantified by densitometric analysis by using Scion (Frederick, MD) Image Beta 4.0.2 Gel Plot 2 and adjusted for $\beta$-actin.

Behavioral experiments. The Morris water maze experiments were performed as described previously (van Praag et al., 1999). Briefly, the animals were subjected to $1 \mathrm{~d}$ of acclimation, followed by $6 \mathrm{~d}$ of training ( 4 trials/d) and a probe trial $24 \mathrm{~h}$ later. All trials were videotaped by using an overhead CCD camera attached to a videocassette recorder. Swimming speed (relative swimming distance per unit time), quadrant analysis (percentage of time spent in the correct quadrant), and probe trial (percentage of time spent in the correct quadrant and number of platform crossings) were all determined by videotape analysis.

Statistical analysis. StatView 5.0 for Macintosh was used for all analyses (ANOVA with Bonferroni post hoc analysis; significance set at $p<0.05$ ) except for the Morris water maze studies. Escape latency times on the Morris water maze were analyzed by using a repeated-measures ANOVA [SPSS (Chicago, IL) 11.0 for Mac OS X] with group (run and sedentary) as the between-subjects factor and the $6 \mathrm{~d}$ of trials as the within-subjects factor. To characterize where these differences were smaller and larger, we used tests of simple effects.

\section{Results}

Animals in the long-term running group showed an increase in their average running distance across the course of the experiment. The average running distance at week 2 was $2652 \pm 546$ $\mathrm{m} /$ night and at week 20 was $4287 \pm 464 \mathrm{~m} /$ night $\left(R^{2}=0.78\right)$.

\section{Long-term voluntary exercise reduces $\mathrm{A} \beta$ load in TgCRND8 animals}

TgCRND8 mice given access to running wheels showed a significant decrease $(38 \% ; p=0.018)$ in $\mathrm{A} \beta$ in the frontal cortex, a significant decrease $(53 \% ; p=0.0003)$ in $A \beta$ in the cortex at the 
level of the hippocampus, and a decrease in $\mathrm{A} \beta(40 \% ; p=0.06)$ in the hippocampus compared with sedentary animals (Fig. 1). This decrease in extracellular $A \beta$ also was paralleled by a decrease in total formic acid-extractable $\mathrm{A} \beta$, as measured by ELISA. Exercising animals had significantly reduced levels of cortical $\mathrm{A} \beta 1-40$ $(35 \% ; p=0.005)$ and $\mathrm{A} \beta 1-42(22 \% ; p=0.04)$ compared with sedentary animals.

To test the hypothesis that voluntary exercise could mediate specifically the pathway of APP metabolism, we examined the levels of total APP protein (antibody 22C11), the C-terminal fragments (CTFs; both $\alpha$-CTF and $\beta$-CTF) of APP (antibody CT20), and the level of secretase activity (R \& D Systems). There was no significant decrease in the exercise group in the steadystate levels of total APP, CTFs, or $\alpha$-, $\beta$-, and $\gamma$-secretase.

\section{Long-term voluntary exercise enhances the rate of learning in TgCRND8 animals}

Exercised animals showed an enhanced acquisition of the task on day 1 , as evidenced by a rapid intertrial improvement in escape latency at this time point. This difference was not a function of a variation in swimming speed because, in agreement with previous reports (van Praag et al., 1999), there was no difference in swim speed between the two groups. Interestingly, exercised animals showed maximal performance on day 2 and did not improve thereafter, whereas sedentary animals improved more slowly across the first $5 \mathrm{~d}$ of trials. Analysis of the average escape latencies demonstrates that they decreased significantly over the $6 \mathrm{~d}\left(F_{(1,5)}=8.5 ; p<0.0005\right)$, and the overall difference between the run and sedentary groups was significant $\left(F_{(1,8)}=11.2 ; p=\right.$ 0.010 ). On days 1,2 , and 3 , the animals in the sedentary group took longer to find the escape platform than those in the run group ( $p$ values of $0.015,0.010$, and 0.020 , respectively). Average times on days 4 and 5 did not differ between groups $(p=0.475$ and $p=0.424)$, and those on day 6 were marginal $(p=0.064)$.

For the quadrant analysis, the overall test of between-subject group differences was not significant $\left(F_{(1,8)}=2.6 ; p=0.146\right)$, but the group-by-time interaction approached significance $\left(F_{(3,24)}=\right.$ $2.9 ; p=0.053)$. Tests of the orthogonal polynomial breakdown of the within-subject sum-of-squares into linear, quadratic, and cubic components indicated a significant quadratic group-by-time interaction $(p=0.038)$. Comparing group means for each day demonstrated that the average percentage of time spent in the correct quadrant was higher in the running group on day 3 ( $p=$ $0.007)$ only.

The probe trial demonstrated that there was no significant difference in the time spent in the correct target quadrant or in the number of platform crossings between groups.

\section{Short-term voluntary exercise mediates APP processing in TgCRND8 animals independently of neprilysin and IDE}

To assess the possibility that exercise was inducing a short-term change in APP processing, we examined the effect of 1 month of exercise in the TgCRND8 animals. In these animals, the level of total APP protein and secretase activity again was unchanged between sedentary and exercise groups $(p>0.3)$. Both the $\alpha$-CTFs and $\beta$-CTFs of APP, however, were reduced significantly in exercising animals ( $54 \%$ and $p=0.04$ for $\alpha$-CTF; $35 \%$ and $p=$ 0.03 for $\beta$-CTF) (Fig. 2). This also was paralleled by a large but nonsignificant decrease in formic acid-extractable $A \beta 1-40$ and $\mathrm{A} \beta 1-42$ ( $51 \%$ and $p=0.29 ; 53 \%$ and $p=0.24$, respectively). To assess the possibility that this reduction in the proteolytic fragments of APP was occurring by one of the classical $A \beta$ degrada-

\section{Sedentary}

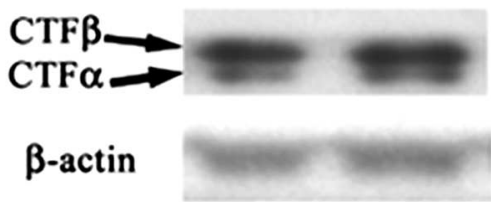

APP
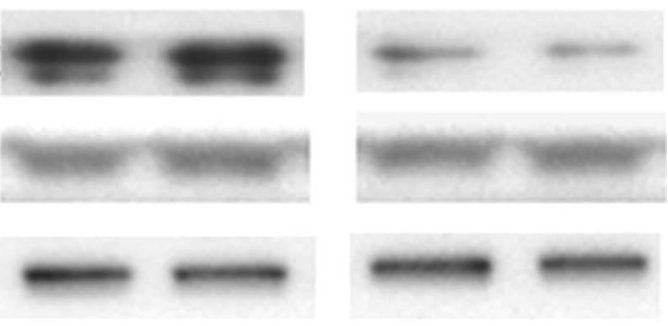

Figure 2. Representative Western blot data from four animals showing no difference in APP or $\beta$-actin but showing significant $(p<0.04)$ reductions in both the $\alpha$-CTF and $\beta$-CTF in the exercising animals compared with the sedentary animals.

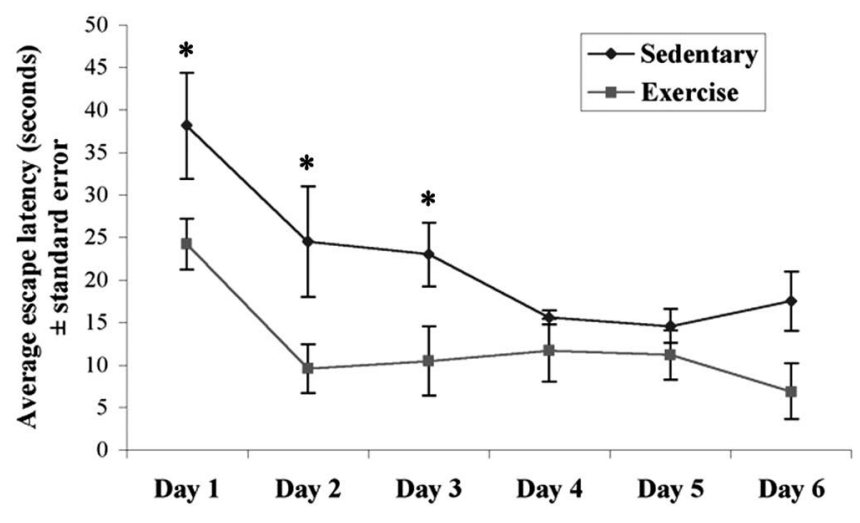

Figure 3. The effect of exercise on Morris water maze performance. Average escape latencies for sedentary and exercising TgCRND8 animals in the Morris water maze are shown. Exercised animals show improved performance across the time course, with significant differences present on the first $3 \mathrm{~d}$ of trials, compared with the sedentary animals $\left({ }^{*} p<0.02\right)$. Error bars indicate $\pm \mathrm{SE}$.

tion pathways, we examined the mRNA and protein levels of neprilysin and IDE. These were all unchanged between groups.

\section{Discussion}

In this study, we demonstrate that increased physical activity can decrease $\mathrm{A} \beta$ levels in the TgCRND8 mouse model of AD. We also demonstrate that the mechanism underlying this effect is likely to be mediated during the early phase of the intervention, when there is a reduction in the proteolytic cleavage products (CTFs) of APP after just 1 month of exercise. This effect may be independent of classical $A \beta$ degradation pathways, because there was no concomitant change in the mRNA or protein levels of neprilysin or IDE and, instead, may involve neuronal metabolism changes that are known to affect APP processing and to be regulated by exercise. Voluntary exercise may, therefore, mediate APP metabolism and the amyloid cascade in favor of reduced production of $\mathrm{A} \beta$. This then may impact learning and memory, as suggested by the improved performance of exercised animals on the Morris water maze task (Fig. 3).

We have demonstrated that voluntary exercise significantly reduces both extracellular $\mathrm{A} \beta$ (as assessed by immunohistochemistry) and total formic acid-extractable $\mathrm{A} \beta 1-40$ and $\mathrm{A} \beta 1-42$ (as assessed by ELISA). This reduction was present in both cortical and hippocampal regions of the brain after long-term exercise and was comparable with the effects seen with interventions such as $\mathrm{A} \beta$ immunization, which resulted in a $50 \%$ reduction in $\mathrm{A} \beta$ in this same transgenic line (Janus et al., 2000). 
Although daily exercise before the onset of AD-like neuropathology is sufficient to slow its progression in the TgCRND8 animal model, additional studies are required to delineate whether less-frequent exercise will be sufficient to produce a similar effect. These studies will be important, because reports on humans suggest that high levels of activity (defined as three or more sessions per week with an intensity level greater than walking) confer the greater benefit of decreasing the incidence of AD relative to less-frequent exercise (Laurin et al., 2001). Furthermore, human studies also demonstrate that a number of outcome measures (including scores on the dementia rating scale, MiniMental State Examination) were improved in $\mathrm{AD}$ patients that had 3 months of aerobic training (Palleschi et al., 1996). It will, therefore, be relevant to assess the effects of exercise begun after the onset of pathology in this transgenic model. In addition, it will be clinically important to assess the precise behavioral effect of exercise in transgenic models of AD. Preliminary data suggest that long-term running in the TgCRND8 animals enhances the rate of learning in the Morris water maze, consistent with other studies in both the human and animal literature (for review, see McAuley et al., 2004) and also with the hypothesis that exercise primes plasticity-related processes that facilitate the encoding of information (Cotman and Berchtold, 2002). This is the first such demonstration that exercise can affect the performance of APP transgenic mice on this task in a manner similar to that which occurs in wild-type animals (Adlard et al., 2004). However, although it is established that the TgCRND8 strain of animals shows deficits on this task compared with wild-type animals (Janus et al., 2000; Chishti et al., 2001), additional studies are required to address fully the possibility that exercise can offset such performance deficits.

Although this is the first study to examine specifically the effect of exercise on $\mathrm{A} \beta$ pathology, a previous study (Jankowsky et al., 2003) examined the effect of environmental enrichment (EE) on the development of $\mathrm{A} \beta$ neuropathology in a transgenic model that had both APP and presenilin-1 mutations. In that study there was an exacerbation of $\mathrm{A} \beta$ pathology in animals subject to EE. Because such paradigms typically incorporate a number of stimuli, including a running wheel, it is not possible to compare them directly to the current investigation. However, it is of note that there were a number of animals in the EE group that had lower $A \beta$ levels than did the controls. Although individual levels of activity were not monitored, it is possible that these differences arose as a function of differential usage of the running wheel. Strain differences also may play a role in these divergent results (the animals in that study and the current one had different mutations, but both were maintained on a B6C3 background) in addition to variations in the timing of the intervention.

To define a potential mechanism underlying the exerciseinduced reduction in $\mathrm{AD}$-like neuropathology, we undertook a series of experiments examining the effect of exercise on $\mathrm{A} \beta$. The level of $A \beta$ present within the brain is a balance between its production and its clearance/degradation. Because $A \beta$ is generated by the proteolytic processing of APP, we examined the hypothesis that exercise was acting directly on APP production. There was no change in total APP, in the C-terminal fragments of APP, or in secretase activity in the exercising animals that would indicate a direct effect of exercise on APP processing after long-term exercise. It is possible, therefore, that exercise may be acting downstream of APP; alternatively, it may result in an acute effect that is not sustained either with advancing age or with the emergence of increasing amounts of neuropathology. We have demonstrated previously that some of the biochemical changes resulting from short-term exercise (4 weeks) may not be maintained with extended periods of activity ( 5 months) (our unpublished data). We therefore examined the hypothesis that the effect of exercise on extracellular $\mathrm{A} \beta$ was occurring during the early stages of the exercise intervention.

We demonstrated that 1 month of voluntary exercise resulted in a decrease in the fragments derived from the proteolytic cleavage of APP. This was independent of changes in steady-state levels of APP, in secretase activity, or in the mRNA or protein of neprilysin and IDE [candidate molecules involved in $\mathrm{A} \beta$ degradation (Leissring et al., 2003)]. Because physical activity modulates a multitude of gene products at both the mRNA and protein level, inducing anatomical, neurochemical, and electrophysiological changes that promote neuronal plasticity (Cotman and Berchtold, 2002), it is possible that multiple pathways may be activated to regulate amyloid levels either directly or indirectly. One possibility, for example, is that there is an exercise-induced upregulation of proteasome activity, as reported previously in muscle (Radak et al., 2000), that can mediate the degradation of the proteolytic fragments of APP (Nunan et al., 2001, 2003; Lopez Salon et al., 2003; Schmitz et al., 2004). A more likely scenario, however, is that exercise is modulating APP metabolism directly (for review, see Turner et al., 2003) by increases in neuronal activity (Lee et al., 2003). For example, APP processing can be augmented by PKC, MAPK (mitogen-activated protein kinase), and phospholipase C (for review, see Turner et al., 2003), and these pathways are known to be activated by exercise (Shen et al., 2001; Molteni et al., 2002; our unpublished observations). In support of the neuronal activity hypothesis, it has also been shown that $M_{1}$ muscarinic agonist treatment decreases $A \beta$ load in a triple transgenic model of AD (Caccamo et al., 2004), consistent with existing reports (for review, see Rossner et al., 1998). Cholinergic activity increases with exercise, and the regulation of the cholinergic system by exercise has been implicated in exercise-induced plasticity (for review, see Cotman and Berchtold, 2002). Together, these findings support the notion of neuronal activity as a possible mechanism for the exercise-mediated regulation of APP processing.

Our findings demonstrate that voluntary exercise can decrease significantly A $\beta$ load in the TgCRND8 transgenic model of $\mathrm{AD}$. Whereas pharmacological interventions have sought to reduce $\mathrm{A} \beta$ to constrain the $\mathrm{AD}$ cascade, we demonstrate here that exercise represents a simple behavioral strategy that may promote a resistance to the development of the neuropathology of $\mathrm{AD}$. These findings provide the first support of existing epidemiological data and warrant additional studies to delineate both the intensity/timing of the exercise required to impact significantly the progression of the disease and the mechanism responsible for the decreased $\mathrm{A} \beta$ levels. Future studies also will allow us to assess the effect of exercise in other transgenic models of $\mathrm{AD}$. In this way we will be better able to translate these studies to the human population.

\section{References}

Adlard PA, Perreau VM, Engesser-Cesar C, Cotman CW (2004) The timecourse of induction of brain-derived neurotrophic factor mRNA and protein in the rat hippocampus following voluntary exercise. Neurosci Lett 363:43-48.

Caccamo A, Oddo S, Billings LM, Blurton-Jones M, Fisher A, LaFerla FM (2004) M1 muscarinic agonist treatment rescues the behavioral deficit present in the 3XTg-AD mice. Soc Neurosci Abstr 30:675.18.

Chishti MA, Yang DS, Janus C, Phinney AL, Home P, Pearson J, Strome R, Zuker N, Loukides J, French J, Turner S, Lozza G, Grilli M, Kunicki S, Morissette C, Paquette J, Gervais F, Bergeron C, Fraser PE, Carlson GA, et 
al. (2001) Early-onset amyloid deposition and cognitive deficits in transgenic mice expressing a double mutant form of amyloid precursor protein 695. J Biol Chem 276:21562-21570.

Cotman CW, Berchtold NC (2002) Exercise: a behavioral intervention to enhance brain health and plasticity. Trends Neurosci 25:295-301.

Cummings BJ, Cotman CW (1995) Image analysis of beta-amyloid load in Alzheimer's disease and relation to dementia severity. Lancet 346:1524-1528.

Friedland RP, Fritsch T, Smyth KA, Koss E, Lerner AJ, Chen CH, Petot GJ, Debanne SM (2001) Patients with Alzheimer's disease have reduced activities in midlife compared with healthy control-group members. Proc Natl Acad Sci USA 98:3440-3445.

Jankowsky JL, Xu G, Fromholt D, Gonzales V, Borchelt DR (2003) Environmental enrichment exacerbates amyloid plaque formation in a transgenic mouse model of Alzheimer disease. J Neuropathol Exp Neurol 62:1220-1227.

Janus C, Pearson J, McLaurin J, Mathews PM, Jiang Y, Schmidt SD, Chishti MA, Home P, Heslin D, French J, Mount HT, Nixon RA, Mercken M, Bergeron C, Fraser PE, St. George-Hyslop PS, Westaway D (2000) A beta peptide immunization reduces behavioural impairment and plaques in a model of Alzheimer's disease. Nature 408:979-982.

Laurin D, Verreault R, Lindsay J, MacPherson K, Rockwood K (2001) Physical activity and risk of cognitive impairment and dementia in elderly persons. Arch Neurol 58:498-504.

Lee TH, Jang MH, Shin MC, Lim BV, Kim YP, Kim H, Choi HH, Lee KS, Kim EH, Kim CJ (2003) Dependence of rat hippocampal c-Fos expression on intensity and duration of exercise. Life Sci 72:1421-1436.

Leissring MA, Farris W, Chang AY, Walsh DM, Wu X, Sun X, Frosch MP, Selkoe DJ (2003) Enhanced proteolysis of beta-amyloid in APP transgenic mice prevents plaque formation, secondary pathology, and premature death. Neuron 40:1087-1093.

Lopez Salon M, Pasquini L, Besio Moreno M, Pasquini JM, Soto E (2003) Relationship between $\beta$-amyloid degradation and the $26 \mathrm{~S}$ proteasome in neural cells. Exp Neurol 180:131-143.

Mayeux R (2003) Epidemiology of neurodegeneration. Annu Rev Neurosci 26:81-104.

McAuley E, Kramer AF, Colcombe SJ (2004) Cardiovascular fitness and neurocognitive function in older adults: a brief review. Brain Behav Immun 18:214-220.

Molteni R, Ying Z, Gomez-Pinilla F (2002) Differential effects of acute and chronic exercise on plasticity-related genes in the rat hippocampus revealed by microarray. Eur J Neurosci 16:1107-1116.
Nunan J, Shearman MS, Checler F, Cappai R, Evin G, Beyreuther K, Masters CL, Small DH (2001) The C-terminal fragment of the Alzheimer's disease amyloid protein precursor is degraded by a proteasome-dependent mechanism distinct from $\gamma$-secretase. Eur J Biochem 268:5329-5336.

Nunan J, Williamson NA, Hill AF, Sernee MF, Masters CL, Small DH (2003) Proteasome-mediated degradation of the C-terminus of the Alzheimer's disease beta-amyloid protein precursor: effect of C-terminal truncation on production of beta-amyloid protein. J Neurosci Res 74:378-385.

Palleschi L, Vetta F, De Gennaro E, Idone G, Sottosanti G, Gianni W, Marigliano V (1996) Effect of aerobic training on the cognitive performance of elderly patients with senile dementia of Alzheimer type. Arch Gerontol Geriatr Suppl 5:47-50.

Pope SK, Shue VM, Beck C (2003) Will a healthy lifestyle help prevent Alzheimer's disease? Annu Rev Public Health 24:111-132.

Radak Z, Sasvari M, Nyakas C, Taylor AW, Ohno H, Nakamoto H, Goto S (2000) Regular training modulates the accumulation of reactive carbonyl derivatives in mitochondrial and cytosolic fractions of rat skeletal muscle. Arch Biochem Biophys 383:114-118.

Rossner S, Ueberham U, Schliebs R, Perez-Polo JR, Bigl V (1998) The regulation of amyloid precursor protein metabolism by cholinergic mechanisms and neurotrophin receptor signaling. Prog Neurobiol 56:541-569.

Schmitz A, Schneider A, Kummer MP, Herzog V (2004) Endoplasmic reticulum-localized amyloid beta-peptide is degraded in the cytosol by two distinct degradation pathways. Traffic 5:89-101.

Selkoe DJ, Schenk D (2003) Alzheimer's disease: molecular understanding predicts amyloid-based therapeutics. Annu Rev Pharmacol Toxicol 43:545-584.

Shen H, Tong L, Balazs R, Cotman CW (2001) Physical activity elicits sustained activation of the cyclic AMP response element-binding protein and mitogen-activated protein kinase in the rat hippocampus. Neuroscience 107:219-229.

Turner PR, O'Connor K, Tate WP, Abraham WC (2003) Roles of amyloid precursor protein and its fragments in regulating neural activity, plasticity, and memory. Prog Neurobiol 70:1-32.

van Praag H, Christie BR, Sejnowski TJ, Gage FH (1999) Running enhances neurogenesis, learning, and long-term potentiation in mice. Proc Natl Acad Sci USA 96:13427-13431.

Wilson RS, Mendes De Leon CF, Barnes LL, Schneider JA, Bienias JL, Evans DA, Bennett DA (2002) Participation in cognitively stimulating activities and risk of incident Alzheimer disease. JAMA 287:742-748. 